\title{
The Effectiveness EM Mudball and Banana Peels for Textile Wastewater Treatment
}

\author{
Mohd Ariff bin Ahmad Nazri ${ }^{\mathrm{a}}$ and Nurul Liyana binti Ghazali \\ Department of Water and Environmental Engineering, University of Tun Hussein Onn Malaysia, Johor Bahru.
}

\begin{abstract}
Textile industrial activities known as a higher consumer of water that involved several processed daily to maintain the quality of fabric that contribute to the water pollution. Wastewater produced from the textiles could lead to the presence of heavy metal contaminant. Meanwhile, heavy metal is one of the contaminants in wastewater and must be overcome with the appropriate treatment process. To overcome the heavy metal issue, the absorption method by organic waste could be used. Effective microorganism (EM) mudballs and banana peels is a method for threating wastewater quality from textiles effluent. EM is a medium that is able to improve water quality without altering the design area while the banana peels act as a nutrient to microorganism growth and have a potential to removed heavy metal contaminant that produced from textiles wastewater. Method that used to carry out this study are through the laboratory experimental for all consider parameters. The result was obtained shows that EM mudball itself are capable to reduce the concentration of BOD and COD as much as $84 \%$ for BOD with the value reduced to $37 \mathrm{mg} / \mathrm{L}$ and $90 \%$ for COD with the value reduced to $89 \mathrm{mg} / \mathrm{L}$. The effectiveness of banana peels added to the EM mudball could be seen by the $70 \%$ of banana peels are well mixed with the EM mudball have the potential to reduce the concentration of BOD, COD and heavy metal contaminant in textiles wastewater as much as $81 \%$ for BOD $(43 \mathrm{mg} / \mathrm{L}), 90 \%$ of COD $(87 \mathrm{mg} / \mathrm{L})$, and $86 \%$ of Zink $\left(\mathrm{Zn}^{2+}\right)$ with the value is $0.065 \mathrm{mg} / \mathrm{L}$. From the comparison of result with the standard
\end{abstract}

\section{INTRODUCTION}

Textile industry has become the most important and rapidly developing sector in Malaysia and generated more wastewater that will affect the quality and quantity of the water [1]. Textile industrial activities known as a higher consumer of water that involved several processed daily to maintain the quality of fabric [2]. Thus, wastewater from textile industries will produced different pollutant which is dyes, surfactants, acids or bases, salts, heavy metals and suspended solid and the contaminant is highly contained $\mathrm{BOD}, \mathrm{COD}, \mathrm{pH}$ and will cause the color of the effluent change into black because of dyes processes.

Due to the severity of heavy metal contamination and potential adverse health impact on the public, efforts must be taken to purify water containing toxic metal ions [2]. The presence of heavy metal in textiles wastewater caused by the chemical that has been used in the printing, coloring, dyeing and bleaching process and contain synthetic chemical which are generally metal based and many of the metal are harmful for human body and aquatic life it is not complied with the permissible limit [3].

Therefore, by carried out both treatment of wastewater that included the treatment of water pollution and heavy metal in water, combination of this method of effective microorganism (EM) and banana peels were used. The EM and banana peels are material that easier to get and as initiative method of treating contaminated water. The combination of these material could be worked to improve the water quality and efficiently to reduce the cost of treatment.

\section{LITERATURE REVIEW}

\subsection{Textile Wastewater}

Textiles industries could generate millions of gallon dye wastewater daily and the percentage of water usage are different by the types of textiles product and between the processes of textiles production. The textile production processed need to consumes high amount of water, the water are mixed well with the chemical substance so that, it will produced high volume of wastewater that will contribute to water pollution [4].

The Printing and dyeing processed for textiles product is often rich in color and will produced wastewater that contained residues of reactive dyes, aromatic compounds, color, heavy metal, salt, surfactant and chemicals such as aerosol, high value of COD and BOD concentration and it could affect the $\mathrm{pH}$ value to become too acidity or alkalinity [5].

Effluent from textile dyeing and printing processed contain dyes, bleaching agents, salts, acids and heavy metals like $\mathrm{Cr}$, $\mathrm{Cu}, \mathrm{Pb}, \mathrm{Zn}, \mathrm{Fe}$ are discharged continuously without a proper treatment, thus the heavy metal contaminant was analyzed and has a value of $\mathrm{Pb}$ is $1.098 \mathrm{mg} / \mathrm{L}, \mathrm{Fe}$ is $0.191 \mathrm{mg} / \mathrm{L}, \mathrm{Cu} 4.66$ $\mathrm{mg} / \mathrm{L}, \mathrm{Cd} 1.98 \mathrm{mg} / \mathrm{L}, \mathrm{Zn} 3.29 \mathrm{mg} / \mathrm{L}, \mathrm{Ni} 0.076 \mathrm{mg} / \mathrm{L}$ and Cr 3.96 $\mathrm{mg} / \mathrm{L}[3]$.

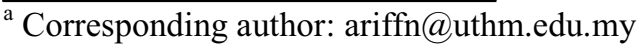




\subsection{Effective Microorganism Mudballs and Banana peels}

EM is effective technology that contains useful microorganism and has a potential to degraded ecosystem that full of harmful microbes, to eliminate the foul smelling odors caused by high levels of ammonia, hydrogen sulphide and methane, and capable to reduce the COD and BOD contaminant and increased the DO for the contaminant water. COD and BOD showed large variations in concentrations during storms [6]. Effective microorganism were able to reduce the amount of BOD as much $93 \%$ while the value of COD was reduced to $20 \%$ and the SS was $94 \%$ (EMRO, 2014).

Banana peels are the product from food waste that have potential as absorbent of removal heavy metal such as $\mathrm{Cu}^{2+}$, $\mathrm{Zn}^{2+}, \mathrm{Co}^{2+}, \mathrm{Ni}^{2+}, \mathrm{Pb}^{2+}, \mathrm{Fe}^{2+}$ from wastewater and converted as adsorbent because they have large surface area, high swelling capacities due to SEM images result with initial condition 5 $\mathrm{mg} / \mathrm{L}$ of $\mathrm{Fe}$ and $\mathrm{Zn}^{2+}[7]$.

\section{METHODOLOGY}

\subsection{Preparation for Banana peels}

Banana peels that have been used in this studies were obtained from the stall at Parit Raja, Batu Pahat. Banana peels were washed repeatedly by using distilled water to removes soluble impurities from their surface of banana peels and banana peels was dried naturally within 24 hours. Afterwards, banana peels was grinded until it become refined and was stored in airtight polyethylene containers.

\subsection{Preparation for EM mudballs}

$50 \mathrm{ml}$ of EM. 1 solution are well mixed with $50 \mathrm{ml}$ molasses and $900 \mathrm{ml}$ distilled water in airtight bottle. The bottle was closed tightly and the cap were loosen regularly when gas formed after couple days to release the gas. The fragmentation processed takes a weeks to activate the EM solution with the $\mathrm{pH}$ value of $\mathrm{EM}$ is 4.0 .

Firstly, Mixed the EM Bokashi with the top soil well. Secondly, activate EM are poured into the mixture of top soil and EM Bokashi until the compound become damp and easily formed. Thirdly, mixture of soil, activate EM and EM Bokashi are rolled until it turns to the shape of tennis ball. EM mudballs were placed into the box that covered with paper.

EM mudballs are kept at a low temperature to encourage the growth of fungi and avoid exposed directly to the sunlight or wind to avoid EM mudballs dries quickly. EM mudballs are ready to use when the entire surface of mudballs is filled fungi. FIGURE 1 show molasses as a solution for activate the EM 1 and EM mudballs preparation.

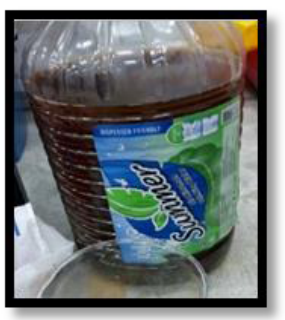

(a)

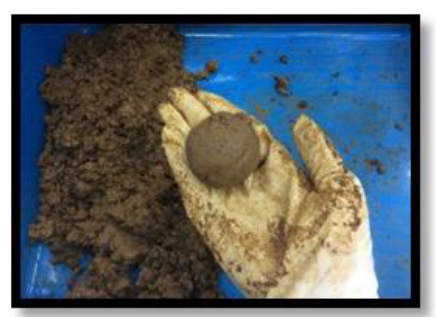

(b)
Figure 1: Activate effective microorganism and EM mudballs preparation

\subsection{Wastewater Sampling}

This study has carried out 5 wastewater sampling at Sri Gading with different percentage of banana peels and EM mudballs such as followed Table 1 shows the percentage of EM mudball and banana peels mixture. EM mudball was thrown into the wastewater tank for sample 2, 3 and 4 once a week to get the percentage of removal BOD, COD and heavy metal. Sample 1 is a blank sample that supplied with the oxygen while sample 5 is a blank sample. The oxygen that has been supplied was affect the percentage of oxygen needed in each sample.

Both of this sample were act as a variable sample to obtained oxygen needed for microorganism growth. TABLE 1 shows percentage of EM mudball and banana peels mixture.

i. Sample 2: Sample 2, 70\% of EM are well mixed with the $30 \%$ of banana peels and the oxygen were supplied into the sample

ii. Sample 3: Sample 3 are supplied with the oxygen to help the microorganism in EM mudballs to breakdown the sludge and treated the water. For this sample $100 \%$ of EM mudballs is used without banana peels.

iii. Sample 4: Sample 4 was supplied with the oxygen, and the mixture of $30 \%$ of EM, and $70 \%$ of banana peels.

TABLE 1: percentage of EM mudball and banana peels mixture.

\begin{tabular}{ccc}
\hline \hline Sample & EM mudballs & Banana peels \\
\hline 2 & $70 \%$ & $30 \%$ \\
3 & $100 \%$ & $0 \%$ \\
4 & $30 \%$ & $70 \%$ \\
\hline \hline
\end{tabular}

\subsection{Data Analysis Methods}

Data analysis method are mostly used the procedures described in the APHA 2005 to obtain the average value for the consider parameters through the laboratory test conducted. The type of sample will divided by the number of samples tested and the result will be compared according to the standard of IWK of the 
Environmental Quality Act 1974. All data presented through graphs, charts and analysed using Microsoft excel software.

\section{LABORATORY TEST}

For this studies, AAS test were conducted to carry out the heavy metal contaminant of textiles wastewater at Sri Gading such as $\mathrm{Zn}^{2+}$. The concentration of $\mathrm{Zn}^{2+}$ are low in range and the textiles wastewater are not necessary to prepare the dilution before the test. Others parameter are considered in this studies such as BOD, COD, DO, pH and temperature.

\section{RESULTS AND DISCUSSIONS}

Wastewater from the textiles industry were taken showed the characteristic of parameter such as $\mathrm{pH}$, temperature, DO, $\mathrm{BOD}_{5}, \mathrm{COD}$ and heavy metal such as Zink $\left(\mathrm{Zn}^{2+}\right)$.

Base on the characteristic table, obtained that the $\mathrm{pH}$ having an average value of 7.95 and the temperature is $25^{\circ} \mathrm{C}$ which is permissible. The average concentration of DO for the textile wastewater was showed value of $3.80 \mathrm{mg} / \mathrm{L}$ while the $\mathrm{BOD}_{5}$ is $222 \mathrm{mg} / \mathrm{L}$ and the COD parameter is $1325 \mathrm{mg} / \mathrm{L}$.

The average concentration of the heavy metal obtained in textiles wastewater for $\mathrm{Zink}\left(\mathrm{Zn}^{2+}\right)$ is $0.568 \mathrm{mg} / \mathrm{L}$. The characteristic of textile wastewater shown in TABLE 2.

TABLE 2: Characteristic of Textile wastewater

\begin{tabular}{|l|c|c|c|}
\hline \multirow{2}{*}{ Parameter } & \multicolumn{3}{|c|}{$\begin{array}{c}\text { Concentration of textiles } \\
\text { wastewater }\end{array}$} \\
\cline { 2 - 4 } & Minimum & Maximum & Average \\
\hline $\mathrm{pH}$ & 7.14 & 8.76 & 7.95 \\
\hline Temperature ${ }^{\circ} \mathrm{C}$ & 24 & 26 & $25^{\circ} \mathrm{C}$ \\
\hline $\mathrm{DO}$ & 2.95 & 4.65 & 3.80 \\
\hline $\mathrm{BOD}{ }_{5}$ & 187 & 256 & 222 \\
\hline $\mathrm{COD}$ & 1000 & 1650 & 1325 \\
\hline Zink $\left(\mathrm{Zn}^{2+}\right)$ & 0.450 & 0.686 & 0.568 \\
\hline
\end{tabular}

*all units are in $\mathrm{mg} / \mathrm{L}$ except the $\mathrm{pH}$ and Temperature

\subsection{Dissolved Oxygen Analysis Result}

Dissolved oxygen in the water are important for microorganism growth to capable of oxidizing the biodegradable organic matter in the sample and DO level are depends on the physical, chemical and biochemical activities in water bodies as the oxygen is considered poorly soluble in water [8]. Therefore, air is supplied by air pump to the water sample 2, 3, and 4 meanwhile for the sample 1 oxygen is supplied to the blank sample to comparing the percentage of oxygen needed in sample and act as the variable sample.

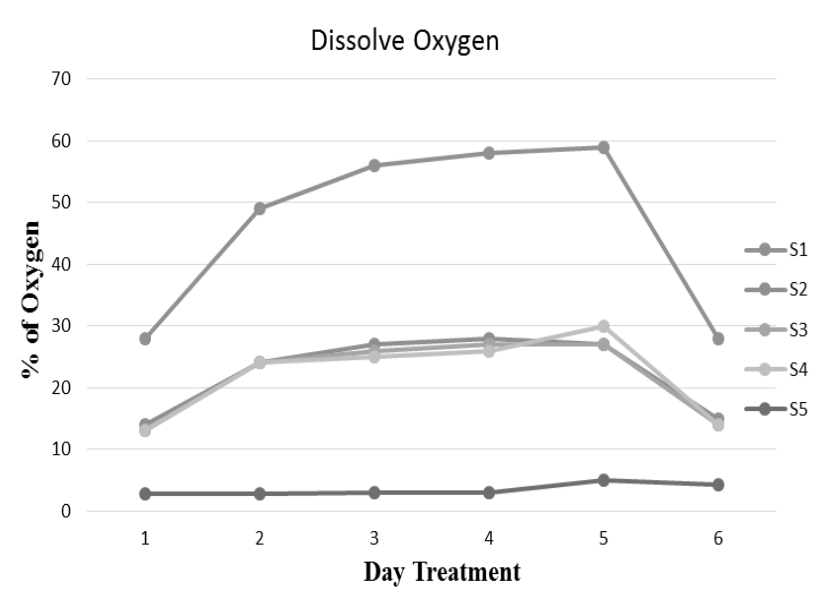

Figure 2: Total dissolved oxygen for textile wastewater treatment by using EM mudballs and banana peels

Sample 1 is representing of blank sample that has been supplied with the oxygen for comparison with the sample 5 (blank sample). The total of oxygen needed for each sample was calculated and compared through the percentage from the blank and supplied oxygen sample (sample 1 ). It is about $50 \%$ oxygen of all textile wastewater sampling needed for the microorganism to growth and biodegrade the organic matter in the wastewater.

FINGURE 2 shows sample 1 is the blank sample that supplied oxygen shows that increasing trend to the DO level from the $28 \%$ on day one supplied to $49 \%$ of DO level on the second day which the value is $4.05 \mathrm{mg} / \mathrm{L}$ to $5.65 \mathrm{mg} / \mathrm{L}$ respectively. The result of third day of oxygen supplied was obtained slowly increasing of DO level from the $56 \%$ with the value is $6.86 \mathrm{mg} / \mathrm{L}$ to the optimum level of DO is $59 \%$ with the value is $7.33 \mathrm{mg} / \mathrm{L}$ and this is because of the oxygen that supplied were enough for microorganism pollutant growth.

\subsection{Biochemical Oxygen Demand Removal}

FIGURE 3 shows that the total BOD removal by using EM mudball and banana peels as textiles wastewater treatment. Sample 2 has the optimum effectiveness removal by $81 \%$ as much as $43 \mathrm{mg} / \mathrm{L}$ and sample 3 are capable to reduce of BOD with the value decreased to $37 \mathrm{mg} / \mathrm{L}$. While the sample 4 could reduce the $\mathrm{BOD}$ as much as $80 \%$ of removal with the value of removal is $47 \% \mathrm{mg} / \mathrm{L}$.

The mixture of banana act as a food to microorganism and the effectiveness of the EM mudball in treated textiles wastewater were affected about $50 \%$ by oxygen needed that have been supplied all the time for microorganism to growth. 


\section{Biochemical Oxygen Demand}

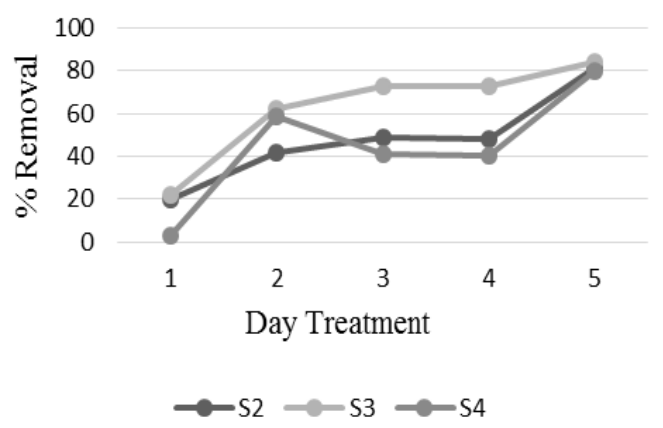

FIGURE 3: Total BOD removal by using EM mudballs and banana peels

\subsection{Chemical Oxygen Demand Removal}

The percentage of COD removal for sample 2 have reached the optimum percentage removal on the fifth day treatment as much as $90 \%$ with the value $87 \mathrm{mg} / \mathrm{L}$. Sample 3 shows the optimum percentage of removal is $90 \%$ with the value of COD is reduced to $89 \mathrm{mg} / \mathrm{L}$. Sample 4 could remove about $72 \%$ of COD in day two of treatment rather than the sample 2 only $31 \%$ of total removal which is $325 \mathrm{mg} / \mathrm{L}$ and $687 \mathrm{mg} / \mathrm{L}$ respectively.

The reducing of COD value is inversely proportional to the increasing value of $\mathrm{DO}$ which is contributed by neutral $\mathrm{pH}$ and this strengthened with statements made by previous studies[9] while the different percentage of banana peels that mixed in EM mudball also affect to the effectiveness of COD removal. FIGURE 4 shows the Total removal of COD by using EM mudball and banana peels.

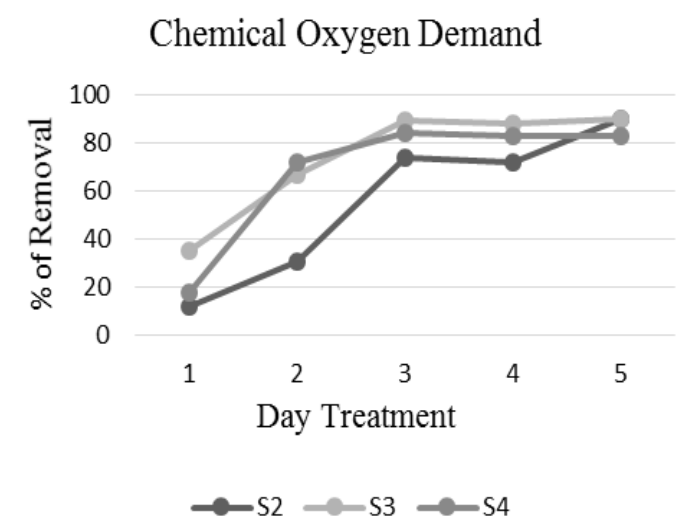

FIGURE 4: Total removal of COD by using EM mudball and banana peels

\subsection{Heavy Metal Zink (Zn2+) Removal}

From the treatment that have been done in this studies, showed that the banana peels has a potential as a medium to remove the heavy metal Zink $\left(\mathrm{Zn}^{2+}\right)$ contaminant in textiles wastewater. FIGURE 5 shows the total removal of Zink $\left(\mathrm{Zn}^{2+}\right)$ by using EM mudball and banana peels

Banana peels could contributed to reduce the heavy metal contaminant Zink $\left(\mathrm{Zn}^{2+}\right)$ about $86 \%$ of removal for sample 4 while the sample 2 has reached $80 \%$ optimum removal of the third day of treatment. The removal of $\mathrm{Zink}\left(\mathrm{Zn}^{2+}\right)$ for sample 3 was increased to $60 \%$ and $78 \%$ of removal on the second and third day of treatment. Therefore, EM has a potential to remove about $89 \%$ of $\mathrm{Zink}\left(\mathrm{Zn}^{2+}\right)$.

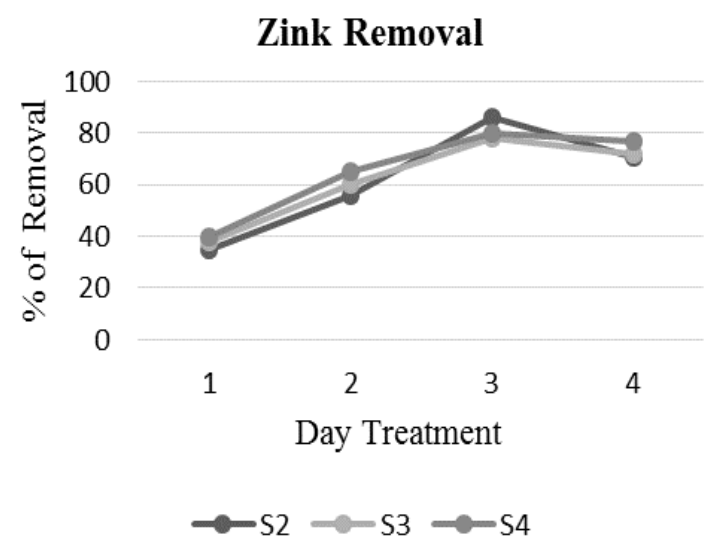

FIGURE 5: Total removal of Zink $\left(\mathrm{Zn}^{2+}\right)$ by using EM mudball and banana peels

\section{CONCLUSIONS}

The result was obtained from the parameter that have been carried out in this studies and it could be concluded that the EM mudball itself are capable to reduce the concentration of BOD, COD and Zink $\left(\mathrm{Zn}^{2+}\right)$ as much as $84 \%, 90 \%$ and $78 \%$ with the value reduced to $37 \mathrm{mg} / \mathrm{L}, 89 \mathrm{mg} / \mathrm{L}$ and $0.097 \mathrm{mg} / \mathrm{L}$ respectively.

The percentage of banana peels shows that $70 \%$ of banana peels well mixed with the EM mudball have the potential to reduce the concentration of BOD, COD and Zink $\left(\mathrm{Zn}^{2+}\right)$ contaminant in textiles wastewater as much as $81 \%(43 \mathrm{mg} / \mathrm{L})$, $90 \%(87 \mathrm{mg} / \mathrm{L})$ and $86 \%(0.065 \mathrm{mg} / \mathrm{L})$ While the $30 \%$ of banana peels could reduce the BOD, COD and Zink $\left(\mathrm{Zn}^{2+}\right)$ as much as by $81 \%, 90 \%$ and $80 \%$ with the value is reduced to 43 $\mathrm{mg} / \mathrm{L}, 87 \mathrm{mg} / \mathrm{L}$ and $0.09 \mathrm{mg} / \mathrm{L}$ respectively.

\section{ACKNOWLEDGEMENT}

I would like to express my gratitude to University Tun Hussein Onn Malaysia for supporting STG grant no U527, Department 
of Water and Environmental Engineering and Micropollutant Research Centre for provide the most advanced laboratory facilities that available through time to fulfill this study.

\section{REFERENCES}

[1] N. Sivri and İ. Toroz, "Pollutants of Textile Industry Wastewater and Assessment of its Discharge Limits by Water Quality Standards," vol. 103, pp. 97-103, 2007.

[2] A. A. Kadir, N. Othman, and N. A. M. Azmi. "Potential of Using Rosa Centifolia To Remove Iron and Manganese in Groundwater Treatment" International Journal of Sustainable Construction Engineering \& Technology vol 3. pp. 70-82, 2012.

[3] M. A. Kamaruddin, M. S. Yusoff, H. A. Aziz, and C. O. Akinbile, "Review Paper Recent Developments of Textile Waste Water Treatment by Adsorption Process : A Review,” vol. 1, no. 4, pp. 60-73, 2013.

[4] J. Rajasthan, "Monitoring of Heavy Metal in Textile Waste Water of," vol. 4, no. 3, pp. 3-6, 2014.

[5] A. Shaikh and T. Engineering, "Water conservation in textile industry," no. November, pp. 48-51, 2009.

[6] R. Nazahiyah, Z. Yusop and I. Abustan, "Stormwater Quality and Pollutant Loading from An Urban Residential Catchment in Johor, Malaysia", vol 56 No 7, pp. 1-9, 2007.

[7] Z. Wang, M. Xue, K. Huang, and Z. Liu, "Textile Dyeing Wastewater Treatment," 2010.

[8] G. A. and D. . L. Juang, Ruey-Shin, "Adsorption of Heavy Metals From Water Using Banana and Orange Peels," no. October, 2015.

[9] C. Principle, Patel H; \& Vashi R. Characterization of Textile Wastewater, 2015. IBN:978-0-12-802326-6. 